University of Navarra

\title{
THE FIVE PHASES IN THE TRANSFER OF HR POLICIES AND PRACTICES WITHIN MNCS
}

\author{
Lourdes Susaeta
}

José R. Pin 


\title{
THE FIVE PHASES IN THE TRANSFER OF HR POLICIES AND PRACTICES WITHIN MNCS
}

\author{
Lourdes Susaeta ${ }^{1}$ \\ José R. Pin ${ }^{2}$
}

\begin{abstract}
The tension that multinational companies (MNCs) suffer in the transfer of their HR policies and practices leads us to take an in-depth look at the factors that affect this transfer. We divide the transfer process into five phases, ranging from the configuration of HR policies and practices in the parent company to their internalization by the subsidiaries' employees, and we analyze this process from six theoretical approaches, presenting the corresponding work hypotheses which will bring about the model of analysis.
\end{abstract}

\footnotetext{
${ }^{1}$ Assistant Research, IESE

${ }^{2}$ Professor, Managing People in Organizations, IESE
}

Keywords: multinational companies (MNCs), subsidiaries, employees, transfer of HR policies and practices. 


\section{THE FIVE PHASES IN THE TRANSFER OF HR POLICIES AND PRACTICES WITHIN MNCS}

The world is facing a series of changes such as globalization, the emergence of regional outposts and a subsequent return to origin. All of this constitutes a phenomenon of increasing interest to the academic world. In the field of social sciences, the dynamics of globalization that promote convergence and divergence in the organization and in management practices have also caught the attention of a wide range of disciplines (Guillen, 2001).

The tension that multinational companies (MNCs) feel in the transfer of their practices is demonstrated by the growing centralization and homogenization of those practices due to the forces of globalization. However, MNCs have also embraced the opportunities and limitations that the countries of origin and their corresponding destinations present, and it is these that determine either standardization or diversity when the subsidiaries implement the practices.

In this complex scenario, the role of the Human Resources (HR) department has acquired an increased importance in the success or failure of the company's international operations (Quintanilla and Ferner, 2003) and therefore, over the last decade or so, there has been great interest in studies of the HR policies used by MNCs and the different factors that executives from the head-quarter company or office ("HQ") use in the transfer of specific practices towards the subsidiary company or office ("the subsidiary"). There are many studies that expound on the policies that are transferred, but there is still a large volume of work to be done on the subject, specifically on how and why these transfers are done, both at a theoretical as well as empirical level.

It is this outstanding work that is at the center of this analysis, which tries to take an in-depth look at the question of this investigation while distinguishing five fundamental steps in the process (Figure 1). In the first place, one has to study the factors that influence the configuration of the HQ policies, which will have been influenced by the country of origin of the MNC. In the second place, we hope to analyze the factors that determine the decision of the HQ to either transfer a practice in a standardized manner or by adapting it to the country to which it is destined. In the third place, we study the negotiation process between the HQ and the subsidiary, in which the subsidiary's role within the MNC, as well as its negotiating power based on the possession of critical resources, are significant. After the negotiation comes the adaptation of the practice by the subsidiary. This adaptation implies the implementation of the practice and its subsequent internationalization by individuals working in the subsidiaries. 


\section{Figure 1}

Phases in the Process of transfer of HR Policies and Practices Within an MNC

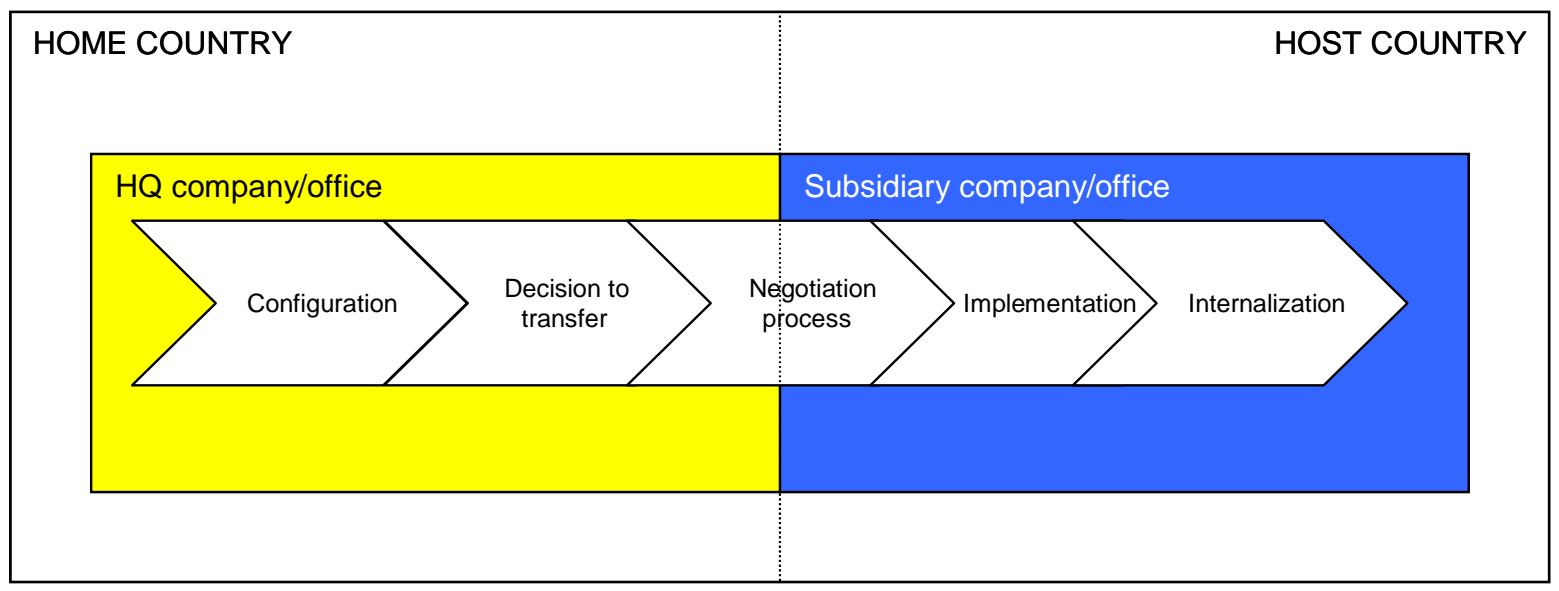

Source: the authors.

In summary, we have formulated five questions for the investigation which correspond to each of the phases of the process:

Q1: What factors influence the configuration of human resource policies in the HQ?

Q2: On what factors would a company base their decision to transfer human resource policies internationally?

Q3: What factors would the negotiation process depend on in the transfer of human resource policies?

Q4: What factors determine the manner in which the subsidiary implements the human resource policies?

Q5: What factors determine the internalization of the policies by subsidiary employees?

In order to respond to the questions of this investigation, it is necessary to review the literature in depth, with the aim of identifying the theoretical lines close to the subject that may help us outline the determining factors in the transfer of HR policies and practices in MNCs.

\section{Transfer of HR Policies and Practices: the Current Debate in Today's Studies}

In the first place, it is necessary to take into account the globalization of the economy, with its trend towards the disappearance of national borders between countries. This brings about a diffusion of specific practices and working systems, resulting in international convergence and the erosion of national differences, at least within the sector (e.g. Katz and Darbishire, 2000). The most common discussion is that the market and technological and management factors push MNCs to adopt cross-border strategies and HR practices, leading to a greater homogenization. In this sense, MNCs are normally seen as a means of internationally transferring and spreading "best practices" (Martin and Beaumont, 1998). 
On the other hand, taking into account the argument from studies based on the institutional sector of the past two decades, and more recently from Hall and Soskice (2001), the national business system and, more importantly, the system of industrial relations determine a distinctive dependence in each country. As Guillen shows (2001, page 246) in his comprehensive vision on the subject: "taking into account the empirical evidence of sociological and socio-political studies, as a whole, diversity is sustainable or at least the resistance of 'cross-national' models amidst the entire globalization process." This disconnection has its roots in the intersection of the globalizing behavior of MNCs, and the persistent variety of the national business systems of the countries where the subsidiaries operate.

The huge institutional complexity of MNCs determines the manner in which they operate in different countries, adopting the characteristics of that particular country in the convergence of national or local practices. At the same time, the pressure of globalization drives the standardization of certain elements of the managerial system, including issues related to personnel, culture, institutional agreements and labor practices (Hall and Soskice, 2001).

The role played by MNCs in promoting or resisting divergence or convergence of HR management across national borders is, in essence, the center of our study.

During the last few years, a great number of studies have focused on the configuration of HR management practices in the MNC's home country and the country of destination, opening a new line of investigation within the field of HR management (Jain et al., 1998; Quintanilla and Ferner, 2003). However, the debate is still in its early stages and presents limitations in both theoretical and empirical aspects (Ferner, 1997).

There are authors, like Sisson (2001, page 5), who argue that there is no need to polarize this debate. This author affirms that what would be better would be to speak of an interaction between the local, national and international influences. At the level of which Sisson speaks, one may add the influence of the forces of the market whose interaction generates greater levels of complexity (Colling and Clark, 2002; Katz and Darbishire, 2000).

\section{Theoretical Approximations in the Study of the Transfer of HR Policies and Practices in MNCs}

One of the most important practices in international business is the transfer of MNC policies and practices throughout the different national businesses they operate. The international transfer is an especially complex process linked to the necessity of the transfer between two international areas with different characteristics. One has to take into account that the practices originate in a very specific institutional environment and are later incorporated into a completely different domain.

Several studies have been undertaken in this area, in which eclectic models are suggested, as well as analyses of the problem from different theoretical points of view. These models are based variously on institutional theory and new institutionalism, the theory of resources, the theory of industrial organization, strategic selection, and so on (Barney and Zajac, 1994; Oliver, 1991; Mauri and Michaels, 1998; Malnight, 2001; Kostova and Roth, 2002; Schuler et al., 1993; Taylor et al., 1996; Quintanilla, 1998). 
In this section, we analyze the six theoretical points of view in the study of the transfer of these practices. Evidently, as in all attempts to classify the ideas of different authors, this is still an artificial classification. However, we do believe it could shed some light since all studies center on the issue we are taking into account, albeit from different points of view. This may help us to obtain a singular and comprehensive vision of what we are analyzing. The authors' contributions are divided into two sections which reflect the two areas in which MNCs operate: the external one, subject to the influence of the country of origin; and the internal one, in which the relationships between subsidiaries in the MNCs network are created. The different points of view and the principal center of the study are summarized in Table 1.

\section{Table 1}

Theoretical Approximations that Study the Transfer of HR Practices Within the MNC

\begin{tabular}{|l|l|l|}
\hline Type of Analysis & Different Approaches & Focus of the analysis \\
\hline $\begin{array}{l}\text { External Analysis } \\
\text { Contextual Factors }\end{array}$ & Cultural & $\begin{array}{l}\text { Centers on the study of the } \\
\text { efficiency of practices in the } \\
\text { measure that these coincide with } \\
\text { the national system of cultural } \\
\text { values. }\end{array}$ \\
\hline $\begin{array}{l}\text { Internal Analysis } \\
\text { Internal Factors }\end{array}$ & $\begin{array}{l}\text { Institutional comparative } \\
\text { of the institutions in the national } \\
\text { business system of the country of } \\
\text { origin and the country of } \\
\text { destination. }\end{array}$ \\
\hline & Structural & $\begin{array}{l}\text { Centers on the influence of the } \\
\text { structural factors of the HQ and } \\
\text { the subsidiary. }\end{array}$ \\
\hline & $\begin{array}{l}\text { Places emphasis on the pressure } \\
\text { that competition exerts in the } \\
\text { companies when it comes to } \\
\text { sharing the "best practices" } \\
\text { through its international } \\
\text { operations. }\end{array}$ \\
\hline Micro-political & $\begin{array}{l}\text { Examines how the agents of the } \\
\text { HQ and the subsidiary would act, } \\
\text { according to their power based on } \\
\text { the critical resources that they } \\
\text { possess. }\end{array}$ \\
\hline $\begin{array}{l}\text { Centers on the knowledge } \\
\text { barriers to reach a common } \\
\text { understanding in the practices. }\end{array}$ \\
\hline
\end{tabular}

\section{External Factors}

In the 1990s, interest grew in the study of the environment of MNCs (Ghoshal and Westney, 1993). The turning point came during a conference that took place in INSEAD in 1989, where a large number of researchers, who studied international companies and specifically their organization, met with numerous researchers who studied the interaction between an organization and its environment. Although there was much controversy during the conference and great resistance in accepting this new line of investigation in the MNC field, it awoke the interest of many researchers from the international business sector. Thus the new line of investigation joined the theory of organization and the study of MNCs, through the institutional theory. 
We contend that this line of thinking highlights the relationship between the organization and its institutional environment, as well as the generic and specific environment which, in great measure, configures the internal organizational structure of the company. The MNCs are subjected to different forces depending on the country where they operate and the sector or sectors in which they are positioned. In the study of this perspective, we will consider three approaches. First, we will consider the cultural approach, which we have included in this section as a previous phase of the institutional trend. Second and third, following Lane's classification (1995), the institutional debate is divided into two lines of thought: the sociological approach of the organization or the institutional comparative (Maurice et al., 1986; Whitley, 1991, 1992 and 1994; Sorge, 1991; Lane, 1989 and 1992) and the new institutionalism (e.g. Hall, 1984 and 1986; Thelen, 1991; Lane 1994 and 1995). These two approaches center on the role of social actors and their influence in the capacity of transformation of the institutions, but the new institutionalism also studies relational factors and, thus, we will study it as a subsection that refers to a mixed analysis.

\section{Cultural Approach}

Culture has been described as the "crystallization of History in thoughts, feelings and actions of the current generation" (Hofstede, 1993, page 5). Other authors complement this definition (Barlett and Ghoshal, 1989, page 42) when they point out that the history, infrastructure, resources and cultural level of a nation affect all aspects of life in that country, including, of course, the behavior of executives.

The traditional cultural approach was the first to study the transfer of HR practices in MNCs. This approach adopts a contingent perspective, arguing that the effectiveness of a determined practice is contingent on its coincidence with the national system of values (Hofstede, 1980). Due to the existence of different national value systems in the countries in which MNCs operate, this theory confirms that the transfer of standard practices from MNCs to their subsidiaries is not possible. On the contrary, the MNC should adapt its practices to the local way of life and thus identify itself with the HR practices of local companies (Newman and Nollen, 1996; Adler and Jelinek, 1986; Schneider, 1986).

From this approach come the following hypotheses:

H1: The national values of a country of origin influence the configuration of HR policies and practices.

H2: The national values of a host country influence the implementation of HR policies and practices.

H3: The national values of a host country influence the internalization of HR policies and practices by the subsidiary's employees.

\section{Comparative Institutional Approach}

Thanks to this more recent perspective, there has been a greater interest in the complexity of the differences between the different national business systems and the institutions that govern the product, labor, and financial markets, and how these interact (e.g. Lane, 1989; Hall and Soskice, 2001; Whitley, 1999). Owing to the differences between nations, there are often multiple restrictions during the internal adaptation of the practices within the MNC (Ferner, 
1997; Whitley, 2001). This institutional comparative approach has its roots in an historical comparative research (Mahoney and Rueschemeyer, 2003).

From this approach, we may put forward the following hypotheses:

H4: The institutional profile of the country of origin will influence the configuration of HR policies and practices.

H5: The institutional profile of the host country will influence the implementation of HR policies and practices.

H6: The existence of a dominant effect in the country of origin will influence the decision of the transfer of HR policies and practices.

\section{Approaches Based on Internal Factors}

In this section, we study the approaches of the studies that analyze internal factors, whether they be of a structural nature, micro-political, rational, or, finally, that based on the transfer of knowledge.

\section{Structural Approach}

In structural terms, the transfer is affected by the role the subsidiary plays within the MNC (Ghoshal and Nohria, 1993), the extension of inter-unit dependence (Taylor et al., 1996), the nature of the internal and external network in which the subsidiary is rooted (Zanfei, 2002), and other structural characteristics that we will analyze in this section.

A subsidiary that is highly integrated within the MNC, and whose function is to execute the strategies formulated by the main office, has a higher probability of being a receptor in the transfer of knowledge and practices (Gupta and Govindarajan, 1991). By contrast, in industries that possess a central structure, where subsidiaries are oriented to serve the local market, there is less pressure in the transfer of practices from the countries of origin (Rosenzweig and Nohria, 1994). On the other hand, the transfer of HR practices from the HQ may be more problematic in the service sector, where there is far more tacit and intangible knowledge than in the manufacturing sector (Gamble, 2003). In their model, Rosenzweig and Nohria (1994) study the transfer of HR practices taking into account structural and contextual factors.

For this approach we may gather the following hypotheses:

H7: The structural factors of the subsidiary will influence the HQ's decision to transfer HR policies and practices.

H7a: If the manner of entry of the country of destination is through the creation of a new subsidiary, the possibility of transfer of HR practices and policies is greater.

H7b: When the age of the subsidiary is lower, the possibility of transfer of HR policies and practices is greater.

H7c: When the size of the subsidiary is smaller, the possibility of transfer of HR policies and practices is greater.

H7d: When the dependence of the subsidiary on local inputs is lower, the possibility of transfer of HR policies and practices is greater. 


\section{Micro-Political Approach}

Regarding how an MNC manages its subsidiaries, conflict arises in the possession of power based on resources, since there may be specific critical assets that gives the subsidiary that possesses them greater superiority over another, or in relation with the HQ, and this affects the degree of autonomy versus dependence.

From this approach, we may gather the following hypothesis:

H8: Power based on resources will influence the negotiation process between the HQ and the subsidiary, in issues related to the transfer of HR policies and practices.

\section{Rational Approach}

The rational approach emphasizes the competitive pressure within a company to share "best practices" through its international operations. This is made clear through some economic theories around MNCs, and is known as internalization (Rugman, 1981). The main idea of this theory is that multinationals have the option to either license or franchise a source of competitive advantage to other companies operating in other countries. However, this contract agreement carries significant risk, not least due to the resulting uncertainty. Those that propose internalization argue that a rational response to this problem is to avoid such transactions by, for example, transferring the competitive advantage only to foreign subsidiaries. Thus, the practice is internalized within the frontiers of the same company. In the empiric studies of employment practices, an example of an approach based on transaction costs can be found in the analysis of Schmitt and Sadowsky (2003), regarding the degree to which foreign MNCs in Germany can count on the developed policies of centralized employment.

With this, we may reach the following hypothesis:

H9: When the HR policies and practices provide a greater advantage for the HQ, the probability of its transfer to the subsidiaries is greater.

And from the theory on strategic election that we suggested as a criticism against the rational approach, we present another hypothesis:

H10: The interests of the managers influence the decision to transfer HR policies and practices.

\section{Knowledge Approach}

This point of view is centered on the internalization of practices by managers and workers of the subsidiary. It is the most recent approach on the subject and includes an analysis of the abilities of people in the subsidiaries, to understand the different HR practices due to factors related to knowledge. Because of the difference in the nature of knowledge and HR practices, Lam (1997) and Bhagat et al. (2002) underline the nature of the knowledge transferred as the pre-requisite and most important element in the efficient transfer of practices across borders.

From this approach, we suggest the following hypothesis:

H11: The nature of the knowledge transferred in HR policies and practices influences the internalization of these by the employees of the subsidiaries. 


\section{Determining Factors and Analysis Models}

The determining factors of the different phases of the transfer appear in Table 2.

\section{Table 2}

Determining Factors in the Transfer of HR Policies and Practices Within an MNC

\begin{tabular}{|c|c|c|}
\hline Phases of the Process & Theoretical Approach & Determining Factors \\
\hline \multirow[t]{2}{*}{ Configuration of the policy } & Cultural Theory & National value system of the country \\
\hline & $\begin{array}{l}\text { Comparative } \\
\text { Institutional Theory: } \\
\text { Affected by country of } \\
\text { origin }\end{array}$ & Institutional profile of the country of origin \\
\hline \multirow[t]{3}{*}{ Decision to transfer } & $\begin{array}{l}\text { Comparative } \\
\text { Institutional Theory }\end{array}$ & Dominant effect of the country of origin \\
\hline & Rational Theory & Best HR practices \\
\hline & $\begin{array}{l}\text { Theory of Strategic } \\
\text { Election }\end{array}$ & $\begin{array}{l}\text { Decision taken by the board is either arbitrary or } \\
\text { reflects interests of the managers }\end{array}$ \\
\hline \multirow[t]{7}{*}{ Negotiation process } & Micro-political Theory & Power based on critical resources \\
\hline & Structural Theory & Role of the subsidiary in the MNC \\
\hline & & Degree of integration in production \\
\hline & & Manner of entry \\
\hline & & Age of the subsidiary \\
\hline & & Size of the subsidiary \\
\hline & & Dependence on local inputs \\
\hline \multirow[t]{3}{*}{ Implementation } & Cultural Theory & National value system of the country of destination \\
\hline & $\begin{array}{l}\text { Comparative } \\
\text { Institutional Theory: } \\
\text { Affected by country of } \\
\text { destination }\end{array}$ & Institutional profile of the country of destination \\
\hline & $\begin{array}{l}\text { Power and } \\
\text { Institutionalism }\end{array}$ & $\begin{array}{l}\text { Response of the agents of the subsidiary to } \\
\text { institutional pressure }\end{array}$ \\
\hline \multirow[t]{4}{*}{ Internalization } & Cultural Theory & $\begin{array}{l}\text { Workers' satisfaction with and commitment to the } \\
\text { HR policies and practices }\end{array}$ \\
\hline & \multirow[t]{3}{*}{ Theory of Knowledge } & $\begin{array}{l}\text { Degree of tacit and explicit knowledge regarding HR } \\
\text { policies and practices }\end{array}$ \\
\hline & & $\begin{array}{l}\text { Manner of communication of HR policies and } \\
\text { practices to employees }\end{array}$ \\
\hline & & Use of IT in HR policies and practices \\
\hline
\end{tabular}


Figure 2 shows a model for analysis that picks up the relationship between the research questions and the theories that point out the different hypothesis proposed in the study.

Figure 2

Analysis Model

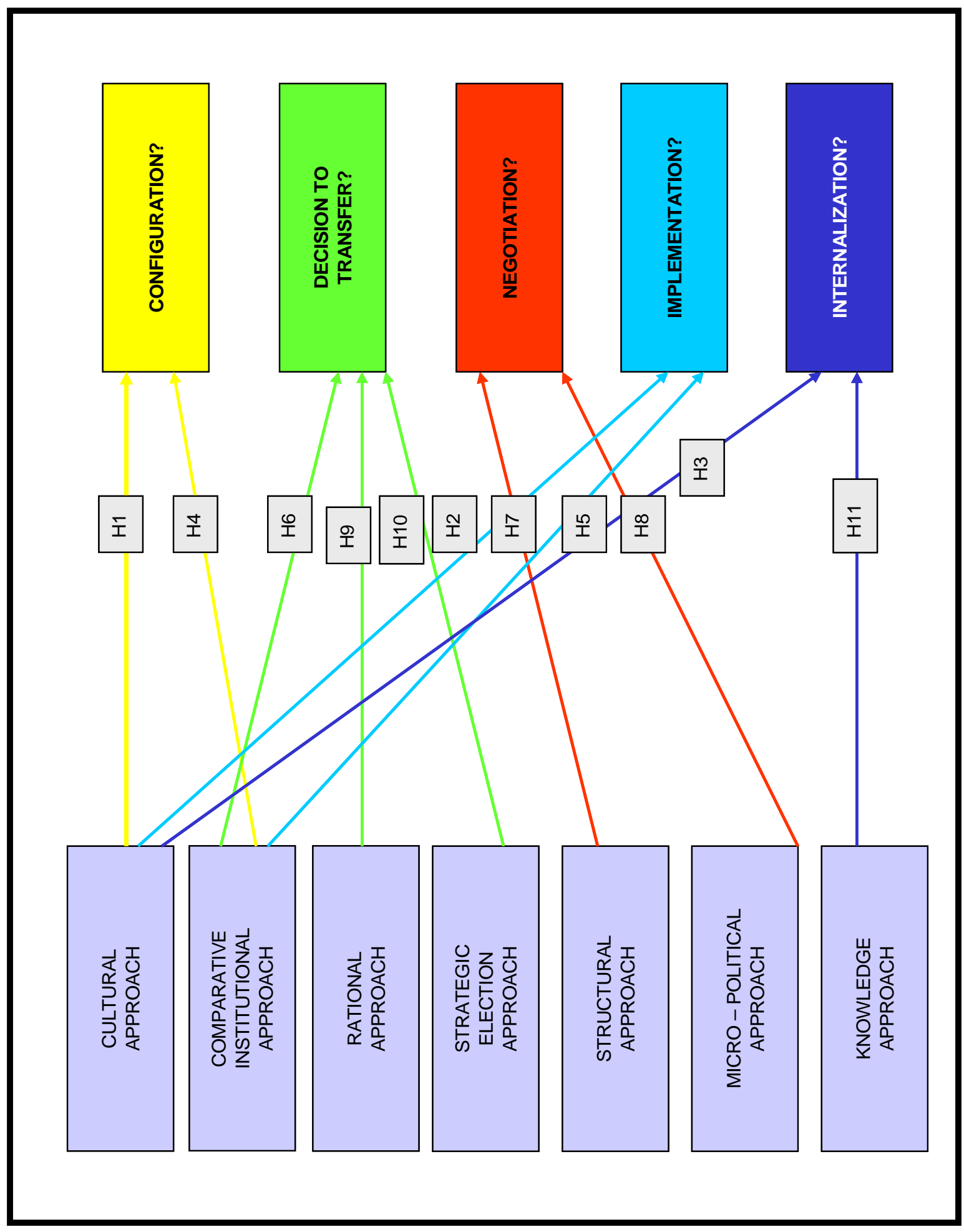

Source: the authors 
In order to clarify the model to be used for the analysis, Table 3, below, presents a double-entry matrix (research questions - theoretical approaches) with the classification of the different hypotheses of this study.

\section{Table 3}

Hypotheses of the Study According to Research Questions and Theoretical Approaches

\begin{tabular}{|l|c|c|c|c|c|c|c|}
\hline & $\begin{array}{c}\text { A. } \\
\text { Cultural }\end{array}$ & $\begin{array}{c}\text { A.1 } \\
\text { Comparative }\end{array}$ & $\begin{array}{c}\text { A. } \\
\text { Structural }\end{array}$ & $\begin{array}{c}\text { A. } \\
\text { Rational }\end{array}$ & $\begin{array}{c}\text { A. } \\
\text { Strategic } \\
\text { Elements }\end{array}$ & $\begin{array}{c}\text { A. } \\
\text { Micro- } \\
\text { political }\end{array}$ & $\begin{array}{c}\text { A. } \\
\text { Knowledge }\end{array}$ \\
\hline Configuration & $\mathrm{H} 1$ & $\mathrm{H} 4$ & & & & & \\
\hline $\begin{array}{l}\text { Transfer } \\
\text { decision }\end{array}$ & & $\mathrm{H} 6$ & $\mathrm{H} 7$ & & & & \\
\hline Negotiation & & & & $\mathrm{H} 9$ & $\mathrm{H} 10$ & $\mathrm{H} 8$ & \\
\hline Implementation & $\mathrm{H} 2$ & $\mathrm{H} 5$ & & & & & \\
\hline Internalization & $\mathrm{H} 3$ & & & & & & $\mathrm{H} 11$ \\
\hline
\end{tabular}

\section{Conclusions}

Throughout this paper, we have studied different theoretical approaches in the transfer of HR policies and practices within MNCs. We have tried to contribute greater clarity to the existing debate, regarding the tension between a trend towards global convergence and the necessary adaptation of HR practices, depending on the characteristic idiosyncrasies of the countries of destination.

The contribution that this study hopes to make to the research, regarding the transfer of HR practices within the MNC, can be summarized in two points:

- The differentiation within the process of transfer of HR practices into five subphases: configuration, transfer decision-making, negotiation, implementation and internalization. Why and how they are produced, make up the questions of our research.

- In order to answer the questions, we present an integrating and eclectic model of the different theoretical approaches that do not exclude any but instead complement one another.

This debate is acquiring greater importance in the study of the strategic role of subsidiaries, within the organizational network of the MNC. The transfer of specific practices always constitutes a decision from the HQ that is influenced by the characteristics of the country of origin of the MNC. These national peculiarities condition the transfer but do not determine it, since the final decision would come from the board of the MNC. The path from the configuration to the internalization of the practice is what we hoped to pick up in our model of analysis, with the elements that either favor or limit them.

We would also like to underline that HR practice and policy in subsidiaries should never be studied in an isolated manner, since it is necessary to know the factors linked to their 
development, in order to understand them completely. Due to the fact that each subsidiary is unique and different from all the others, the HR policies and practices in the subsidiaries differ according to their degree of centralization and integration.

\section{Limitations}

This study contains two limitations, due to its generic approach and its theoretical nature.

In the first place, during the undertaking of the model, we have tried to take into account only indirectly the types of structural organization that the MNC may adopt, and on which we focus in section two. The approach of our working hypotheses would be different if the MNC possessed a multi-domestic, global or transnational organizational structure. Our study tackles the general problem of the transfer, but undoubtedly one has to recognize that, in an MNC with a multi-domestic internal configuration, HR practices tend to adapt to the local context. In a global MNC, there is a greater level of homogenization in the practices, centralizing configuration and control from the main office. In this case, local adaptation would be motivated by fundamentally legal issues, and by institutional pressure that the MNC cannot bypass in its activity in the country of destination. If the MNC is transnational, the subsidiaries enjoy greater independence due to their strategic role within the network. In this case, it would be interesting to study the relationships in the transfer of practices between subsidiaries and the main office, since it is possible that a practice is implemented in a subsidiary as a 'trial', or that it arises as an initiative from the managers of that office. Should it be successful, the transfer of this "best practice" to the MNC is then called "inverse diffusion".

In the second place, since it is a general study, the effects of the sector, in terms of context, have been indirectly taken into account. Given the important influence that the sector exercises on the MNCs, it would be necessary to synthesize the key characteristics of the sector in which subsidiaries operate. Without an adequate understanding of the role of the sector, it would be easy to think that some particular characteristics of the processes in a subsidiary are the due to the peculiarities of its country of origin when, in reality, they are a result of the forces that mold the sector in which the company operates, or vice versa. This possible confusion is even greater in big MNCs with activities in different businesses and working in many countries. It is not possible to isolate the study of a company from its sector, since this is what constitutes the specific environment in which it operates. For an MNC with operations in different countries, the study of the sector is even more important, because when an MNC arrives in a new country, its management, among other things, should become familiar with the management praxis of the said country, with the needs of their clients and with the legal environment of the sector in that country. 


\section{References}

Adler, N. and M. Jelinek (1986), "Is Organization Culture - Culture Bound?," Human Resource Management, 25, 1, pp. 73-90.

Barney, J. and E. J. Zajac (1994), "Competitive Organizational Behaviour: Toward an Organizationally-Based Theory of Competitive Advantage," Strategic Management Journal, 15, pp. 5-9.

Bartlett, C. and S. Ghoshal (1989), "Managing Across Borders: The Transnational Solution," HBS Press, Boston.

Bhagat, R., B. Kedia, P. Harveston, and H. Triyis (2002), "Cultural Variations in the Crossborder Transfer of Organizational Knowledge: An Integrative Framework," Academy of Management Review, 27, 2, pp. 204-222.

Colling, T. and I. Clark (2002), "Looking for 'Americanness': Home-Country, Sector and Firm Effects on Employment Systems in an Engineering Services Company," European Industrial Relations Journal, 3 (November).

Ferner, A. (1997), "Country of Origin Effects y Human Resource Management in Multinational Companies," Human Resource Management Journal, 7, 1, pp. 19-37.

Ghoshal, S. and E. Westney (1993), "Organization Theory and the Multinational Corporation," St. Martin Press, Cambridge.

Guillen, M. (2001), "Is Globalization Civilizing, Destructive or Feeble? A Critique of Five Key Debates in the Social Science Literature," Annual Review of Sociology, 27, pp. 235-260.

Gupta, A. K. and V. Govindarajan (1991), "Knowledge Flows and the Structure of Control within Multinational Corporations," Academy of Management Review, 16, 4, pp. 768-792.

Hall, P. (1984), "Patterns of Economic Policy: an Organizational Approach," in S. Bornstein, D. Held, and J. Krieger (eds.), "The State in Capitalist Europe," Unwin Hyman, London, pp. 124138.

Hall, P. (1986), “Governing the Economy,” Oxford University Press, London.

Hall, P. and D. Soskice (eds.) (2001), "Varieties of Capitalism: The Institutional Foundations of Comparative Advantage," Oxford University Press, Oxford.

Hofstede, G. (1980), “Culture's Consequences: International Differences in Work related Values,” Sage Publications, Beverly Hills.

Hofstede, G. (1993), "Intercultural Conflict and Synergy in Europe. Management in Western Europe," in D. J. Hickson (eds.), "Society, Culture and Organization in Twelve Nations," Walter de Gruyter, Nueva York, pp. 1-8.

Jain, H., J. Lawler, and M. Morishima (1998), "Multinational Corporations, Human Resource Management and Host-country Nationals," The International Journal of Human Resource Management, 9, 4, pp. 553-566. 
Katz, H. and 0. Darbishire (2000), "Converging Divergences: Worldwide Changes in Employment Systems," Cornell University Press, Ithaca.

Kostova, T. and K. Roth (2002), "Adoption of an Organizational Practice by Subsidiaries of Multinational Corporations: Institutional and Relational Effects," Academy of Management Journal, 45, 1, pp. 215-233.

Lam, A. (1997), "Embedded Firms, Embedded Knowledge: Problems of Collaboration and Knowledge Transfer in Global Cooperative Ventures," Organization Studies, 18, 6, pp. 973-997.

Lane, C. (1989), "Management and Labour in Europe. The industrial Enterprise in Germany, Britain y France,” Edward Elgar, Aldershot.

Lane, C. (1992), "European Business Systems: Britain and Germany compared," in R. Whitley, (ed.), "European Business Systems, Firms and Markets in their National Contexts," Sage Publications, London, pp. 64-97.

Lane, C. (1994), “Industrial Order and the Transformation of Industrial Relations," London.

Lane, C. (1995), "Industry and Society in Europe. Stability and Change in Britain, Germany and France," Edward Elger, Aldershot.

Mahoney, J. and D. Rueschemeyer (eds.) (2003), "Comparative Historical Analysis in the Social Sciences,” Cambridge University Press, Cambridge.

Malnight, T. W. (2001), "Emerging Structural Patterns within Multinational Corporations: Toward Process-Based Structures,” Academy of Management Journal, 44, 6, pp. 1.187-1.210.

Martin, G. and P. Beaumont (1998), "Diffusing 'Best Practices' in Multinational Firms: Prospects, Practice and Contestation," International Journal of Human Resource Management, 9, 4, pp. 671-695.

Mauri, A. J. and M. P. Michaels (1998), "Firm and Industry Effects within Strategic Management: An Empirical Examination,” Strategic Management Journal, 19, pp. 211-219.

Maurice, M., F. Sellier, and J. J. Silvestre (1986), "The Social Foundations of Industrial Power. A Comparison of France y Germany,” MIT Press, Cambridge.

Newman, K. and S. Nollen (1996), "Culture and Congruence: The Fit Between Management Practices and National Culture," Journal of International Business Studies, 27, 4, pp. 753-779.

Oliver, C. (1991), "Strategic Responses to Institutional Processes," Academy of Management Review, 16, pp. 145-179.

Quintanilla, J. (1998), "The Configuration of Human Resources Management Policies and Practices in Multinational Subsidiaries: The case of European retail banks in Spain," Doctoral Thesis, University of Warwick.

Quintanilla, J. and A. Ferner (2003), "Multinationals and Human Resource Management: between Global Convergence and National Identity," International Journal of Human Resource Management, 14, 3, pp. 363-368.

Rosenzweig, P. and N. Nohria (1994), "Influences on Human Resource; Management Practices in Multinational Corporations," Journal of International Business Studies, 25, 2, pp. 229-251. 
Rugman, A. M. (1981), “Inside the Multinationals: The Economics of Internal Markets," Croom Helm, London.

Schmitt, M. and D. Sadowski (2003), "A Cost-Minimisation Approach to the International Transfer of HRM/IRM practices: Anglo-Saxon Multinationals in the Federal Republic of Germany," International Journal of Human Resource Management.

Schuler, R., P. Dowling, and H. De Cieri (1993), "An Integrative Framework of Strategic International Human Resource Management," International Journal of Human Resource Management, 4, 4, pp. 717-762.

Sisson, K. (2001), "Reflections on the Papers, presented to the DMU-IESE conference on Multinational Companies and HRM: Between Globalisation and National Business Systems," Leicester Business School, De Montfort University, 12-14 July.

Sorge, A. (1991), "Strategic Fit and the Societal Effect: Interpreting Cross-National Comparisons of Technology, Organization and Human Resources," Organization Studies, 12/2, pp. 161-190.

Taylor, S., S. Beechler, and N. Napier (1996), "Toward an Integrative Model of Strategic International Human Resource Management," Academy of Management Review, 21, 4, pp. 959985.

Thelen, K. (1991), "Union of Parts: Labor Politics in Postwar Germany," Cornell University Press, Ithaca, NY.

Whitley, R. (1991), “The Societal Construction of Business Systems in East Asia," Organization Studies, 12, 1, pp. 1-28.

Whitley, R. (1992), "European Business Systems: Firms and Markets in their National Contexts," Sage, London.

Whitley, R. (1994), "Societies, Firms and Markets: The Social Structuring of Business Systems," in R. Whitley (ed.), "European Business Systems. Firms y Markets in their National Contexts," Sage, London, pp. 5-45.

Whitley, R. (2001), “How and Why are International Firms Different?” in Morgan, Glenn, Peer Hull Kristensen, and Richard R. Whitley (ed.), "The Multinational Firm: Organizing Across Institutional and National Divides," 0xford University Press, Oxford, pp. 27-68.

Zanfei, A. (2002), “Transnational Firms \& the Changing Organisation of Innovative Activities," Cambridge Journal of Economics, 24, pp. 515-542. 